\title{
Pincher-Mediated Macroendocytosis Underlies Retrograde Signaling by Neurotrophin Receptors
}

\author{
Gregorio Valdez, ${ }^{1}$ Wendy Akmentin, ${ }^{1}$ Polyxeni Philippidou, ${ }^{1}$ Rejji Kuruvilla, ${ }^{2}$ David D. Ginty, ${ }^{2}$ and Simon Halegoua ${ }^{1}$ \\ ${ }^{1}$ Department of Neurobiology and Behavior, Center for Brain and Spinal Cord Research, State University of New York at Stony Brook, Stony Brook, New \\ York 11794-5230, and 2Department of Neuroscience, Howard Hughes Medical Institute, The Johns Hopkins University School of Medicine, Baltimore, \\ Maryland 21205
}

\begin{abstract}
Retrograde signaling by neurotrophins is crucial for regulating neuronal phenotype and survival. The mechanism responsible for retrograde signaling has been elusive, because the molecular entities that propagate Trk receptor tyrosine kinase signals from the nerve terminal to the soma have not been defined. Here, we show that the membrane trafficking protein Pincher defines the primary pathway responsible for neurotrophin retrograde signaling in neurons. By both immunofluorescence confocal and immunoelectron microscopy, we find that Pincher mediates the formation of newly identified clathrin-independent macroendosomes for Trk receptors in soma, axons, and dendrites. Trk macroendosomes are derived from plasma membrane ruffles and subsequently processed to multivesicular bodies. Pincher similarly mediates macroendocytosis for NGF (TrkA) and BDNF (TrkB) in both peripheral (sympathetic) and central (hippocampal) neurons. A unique feature of Pincher-Trk endosomes is refractoriness to lysosomal degradation, which ensures persistent signaling through a critical effector of retrograde survival signaling, Erk5 (extracellular signal-regulated kinase 5). Using sympathetic neurons grown in chamber cultures, we find that block of Pincher function, which prevents Trk macroendosome formation, eliminates retrogradely signaled neuronal survival. Pincher is the first distinguishing molecular component of a novel mechanistic pathway for endosomal signaling in neurons.
\end{abstract}

Key words: apoptosis; axon; neurite; nerve growth factor (NGF); pheochromocytoma (PC12); trophic; trafficking; ERK; signal transduction; neurotrophin; endocytosis; clathrin independent

\section{Introduction}

The neurotrophin (NT) family of target-derived growth factors regulates neuronal survival and physiology in both the peripheral nervous system and the CNS (Levi-Montalcini, 1987; Lewin and Barde, 1996). NT signaling occurs through the Trk receptor tyrosine kinases after binding the specific ligands NGF (TrkA), BDNF (TrkB), and NT3 (TrkC). Signal transduction by the receptors is mediated by various effector pathways, which elicit long-term regulation of cell physiology and survival by altering patterns of gene expression (Segal, 2003).

The highly asymmetric neuronal morphology has necessitated evolution of a specialized NT signaling system that is initiated in distal axons and axonally propagated back to the soma. Mechanistic studies in neurons have relied primarily on chamber cultures in which axons are separated from somas. These studies have shown that both NT and Trk are retrogradely transported up the axon via microtubules (Hendry et al., 1974; Ehlers et al.,

Received Dec. 14, 2004; revised April 19, 2005; accepted April 21, 2005.

This work was supported by National Institutes of Health Grant NS18218 (S.H.) and by the Howard Hughes Medical Institute (D.D.G.). We thank P. Brehm and G. Mandel for helpful discussions, N. Mendell for the statistical analyses, J. Rosenbaum for valuable technical assistance, M. Goldfarb for providing the EGFR/TrkB construct, D. Kaplan for the anti-TrkBin antibody, M. Chao for the TrkA construct, and R. Segal for the TrkB-GFP adenovirus.

Correspondence should be addressed to Simon Halegoua, Department of Neurobiology and Behavior, Center for Brain and Spinal Cord Research, State University of New York at Stony Brook, Stony Brook, NY 11794-5230. E-mail: simon.halegoua@sunysb.edu.

DOI:10.1523/JNEUROSCI.5104-04.2005

Copyright $\odot 2005$ Society for Neuroscience $\quad$ 0270-6474/05/255236-12\$15.00/0
1995), an event that appears to be required for signal propagation (Ginty and Segal, 2002). However, the identification of an ultrarapid, ligand-independent component of retrograde phosphorylated Trk (P-Trk) propagation has questioned the necessity for NT/Trk retrograde transport (MacInnis and Campenot, 2002) and has led to proposals of Trk-generated retrograde signaling intermediates (Campenot and MacInnis, 2004; Howe and Mobley, 2004). Neuronal survival is in part mediated by Trk retrograde signals that lead to activation of the transcription factor cAMP response element-binding protein (Riccio et al., 1997). Retrograde signaling at the soma may be selective for specific MAP (mitogen-activated protein) kinase effectors such as Erk5 (extracellular signal-regulated kinase 5) (Watson et al., 2001), although putative Trk signaling endosomes associated with Erk1/2 have been identified (Howe et al., 2001; Delcroix et al., 2003). An important step toward resolving the controversies is the unambiguous identification of the specific molecules and structures that mediate Trk retrograde signaling.

The first vesicular mechanism proposed for retrograde signaling espoused the idea of an endosomal vesicle containing NGF, its receptor, and associated signaling effectors, which was internalized at the nerve terminal and retrogradely transported to the soma (Halegoua et al., 1991). The identification of cytoplasmic vesicles containing Trk receptors lent credence to this model (Beattie et al., 1996), and recent studies indicated that endosomal signaling is the major retrograde mechanism for neuronal survival (Ye et al., 2003; 
Heerssen et al., 2004). To provide a viable retrograde signaling vehicle, the internalized Trk endosome must engage the microtubule-based transport machinery, avoid degradation or recycling, and selectively recruit specific signaling complexes to regulate gene expression. No endocytic mechanism for Trks in neurons has been identified that would satisfy these requirements. Although evidence exists for a role for clathrin in Trk endosome formation (Howe et al., 2001), it is unknown whether it is required for Trk retrograde signaling. Additionally, because clathrin-based endocytosis is involved normally in lysosomal degradation and/or recycling to the plasma membrane, this mechanism is not ideally suited for retrograde signaling in neurons. Indeed, several features of Trk signaling suggest alternative modes of Trk internalization. For example, Trk activation is seen at membrane ruffles where macropinocytosis occurs (Shao et al., 2002; Jullien et al., 2003) and with cholesterol-enriched membrane rafts (Bilderback et al., 1999; Huang et al., 1999) in which caveolas are internalized. However, a link between these specific modes of internalization and Trk retrograde axonal signaling has not been explored.

We recently identified a membrane trafficking protein, Pincher (pinocytic chaperone), that mediates internalization of activated TrkA in pheochromocytoma PC12 cells at plasma membrane ruffles (Shao et al., 2002). Here, we sought to determine whether Pincher-mediated internalization is responsible for Trk-signaling endosomes and retrograde signaling in neurons.

\section{Materials and Methods}

Cell culture. Superior cervical ganglia (SCGs) and hippocampi were dissected from postnatal day 1 (P1) and embryonic day 18 (E18) Sprague Dawley rats, respectively. SCG neurons were dissociated, plated onto collagen-coated tissue culture dishes or glass slides, and maintained as described previously (Mains and Patterson, 1973; Geetha and Wooten, 2003; Ye et al., 2003). Hippocampi were dissociated, plated onto poly-Dlysine-coated glass slides, and cultured as described previously (Matsuoka et al., 1998). PC12 cells (Greene and Tischler, 1976) and TrkAPC12 (Hempstead et al., 1992) were grown on tissue culture dishes or polylysine plus laminin-coated dishes in DMEM supplemented with 5\% fetal bovine serum (FBS) and 10\% horse serum.

Real-time quantitative PCR. Total cellular RNA was isolated from $8 \mathrm{~d}$ cultured SCGs or freshly isolated E18 hippocampi using the RNAeasy kit (Qiagen, Hilden, Germany) and treated with RNAase-free DNase I (Roche Products, Welwyn Garden City, UK) for $30 \mathrm{~min}$ at $37^{\circ} \mathrm{C}$. The RNA was reversed transcribed using SuperScript (Invitrogen, San Diego, $\mathrm{CA}$ ) and random primers to generate cDNA. Real-time PCR was performed using the ABI Prism sequence detector 7700 (Applied Biosystems, Foster City, CA) with SYBR Green PCR core reagents and Pincher $3^{\prime}$ untranslated region-specific primers (forward, 5'TGCCACTGACTTGCTGAATGTC3'; reverse, 5'TGCCCTACATATGAGGAAACTGAG3') or rat glyceraldehyde-3-phosphate dehydrogenase (GAPDH) primers (Applied Biosystems) for normalization.

Recombinant cDNA constructs and adenoviruses. The cDNA constructs, rat TrkA in pCMV5 (Yano et al., 2001), epidermal growth factor receptor (EGFR)/TrkB, a chimera containing the EGFR extracellular domain and TrkA juxtamembrane and intracellular regions (Wang et al., 1996), hemagglutinin (HA)-Pincher, and HA-PincherG68E in pCGN-HA (Shao et al., 2002), were used as described in the text. HA-Pincher- and HAPincherG68E-containing defective recombinant adenoviruses were created using the Ad-Easy system (Stratagene, La Jolla, CA). Recombinant adenoviruses containing green fluorescent protein (GFP) (Vaillant et al., 1999), $\beta$-galactosidase (LacZ) plus dynaminK44A (Ye et al., 2003), and TrkB-GFP (Watson et al., 1999) have been described previously. Specific small interfering RNAs (siRNAs) for Pincher (AAGACCACTTTCATCAGATAC) and Eps15 homology domain-containing protein (EHD) 1-3 (AAGAAAGAGCTGGTGAACAAC) were cloned into the shuttle vector 1.0-CMV and recombinant adenoviruses created using the $\mathrm{pSi}$ lencer adeno system 1.0-CMV (Ambion, Austin, TX).

Transfections and viral infections. Transient transfection with Lipofectamine 2000 (Invitrogen) was used to introduce constructs containing HA-Pincher, HA-PincherG68E, TrkA, and EGFR/TrkB into PC12 cells and neuronal cultures that were seeded on polylysine plus laminincoated coverslips. SCG neurons were maintained in C2 medium (Lein et al., 2002) supplemented with $100 \mathrm{ng} / \mathrm{ml} \mathrm{NGF}$ for $24 \mathrm{~h}$, at which time the cells were washed two times with and transfected in DMEM. After $4 \mathrm{~h}$, the cells were washed two times and incubated in DMEM supplemented with $10 \% \mathrm{FBS}, 100 \mathrm{ng} / \mathrm{ml}$ NGF for $48 \mathrm{~h}$. Hippocampal neurons grown on polylysine-coated coverslips were transfected after $5 \mathrm{~d}$ of culture as described above for SCGs. For biochemical analyses by Western blot, the adenoviruses were titered, and cultures were infected in media with low serum ( $1 \%$ horse serum for PC12 cells and 1\% FBS for SCG neurons) to obtain virally encoded gene expression in $70-80 \%$ of the cells. For survival and immunofluorescence studies, $30-40 \%$ of the neurons were infected.

Western blot analysis. Proteins were extracted from PC12 cells, $8 \mathrm{~d}$ cultured SCG neurons, and E18 hippocampi using radioimmunoprecipitation assay (RIPA) buffer and analyzed by Western blot. The following antibodies were used to probe Western blots: rabbit anti-Pincher (1:5000) (Shao et al., 2002), rabbit anti-Trk-C14 (1:250; Santa Cruz Biotechnology, Santa Cruz, CA), rabbit anti-TrkA (1:200; Chemicon, Temecula, CA), mouse monoclonal antibody ( $\mathrm{mAb}$ ) anti-tubulin (1:10,000; Sigma, St. Louis, MO), mouse mAb anti-HA (1:200; Santa Cruz Biotechnology), and mouse mAb anti-Flag-M5 (1:350; Sigma). Films were analyzed using a Super CoolScan9000ED film scanner (Nikon, Tokyo, Japan), and quantitation of scanned images was done using Image (NIH).

Trk internalization and degradation assays. Internalization and degradation of cell-surface TrkA was assessed using surface TrkA biotinylation. PC12 cells or sympathetic neurons, grown as described above, were cooled to $4^{\circ} \mathrm{C}$ and biotinylated on ice $(1.5 \mathrm{mg} / \mathrm{ml} \mathrm{EZ-Link} \mathrm{NHS-LC-}$ biotin in PBS; Pierce, Rockford, IL) for $20 \mathrm{~min}$. Unreacted biotin was removed in the cold using PBS containing $50 \mathrm{mg} / \mathrm{ml}$ glycine. For TrkA internalization measurements, cells were infected with GFP control virus or with siRNA viruses specific for EHD1-3 or Pincher. To measure surface TrkA remaining after NGF-induced internalization, $72 \mathrm{~h}$ after infection, the cells were NGF treated for 30 min before cell-surface biotinylation, and the cell-surface biotin-TrkA was measured as described below. Internalized TrkA was directly assessed after biotinylation followed by debiotinylation after NGF treatment, as described previously (Kuruvilla et al., 2004). For TrkA degradation measurements, cells infected with viruses containing GFP or Pincher were starved for both serum and NGF for $24 \mathrm{~h}$. After surface biotinylation, the cells were shifted to $37^{\circ} \mathrm{C}$ for $3 \mathrm{~h}$ in the presence of NGF $(100 \mathrm{ng} / \mathrm{ml})$ to allow endocytosis and degradation. Proteins were extracted using RIPA buffer, and detection of biotinylated TrkA was performed as described previously (Kuruvilla et al., 2004). For PC12 cell extracts, equal amounts of protein were used in immunoprecipitations from different samples, and for SCG extracts, Western blot analysis for tubulin in whole-cell extracts was used for normalization.

EGF-Alexa555 internalization. EGF-Alexa555 (Molecular Probes, Eugene, OR) internalization was examined as described previously (Sato et al., 2001), with modification. Forty-eight hours after transfection of EGFR/TrkB chimera and infection with HA-Pincher adenovirus as described above, hippocampal neurons were cooled in DMEM plus $1 \%$ BSA (M-BSA) and treated with ice-cold M-BSA containing $1 \mu \mathrm{g} / \mathrm{ml}$ EGF-Alexa555. After internalization, the cells were incubated with cold M-BSA to terminate internalization, and surface-bound EGF-Alexa555 was removed by washing the cells three times with ice-cold acid-salt solution ( $0.2 \mathrm{~m}$ acetic acid, $\mathrm{pH} 2.8,0.5 \mathrm{M}$ sodium chloride). The cells were then fixed and processed for immunofluorescence microscopy as described below.

Immunofluorescence staining and confocal microscopy. To monitor events in the cell bodies of sympathetic neurons and in cell bodies, axons, and dentrites of hippocampal neurons, the cells were cultured as described above. Before treatments, neurons were neurotrophin and serum 
starved for $2 \mathrm{~h}$. For assessing SCG axons, dissociated neurons were plated on polylysine plus laminin-coated glass slides and $24 \mathrm{~h}$ later infected with adenoviruses as indicated. Thirty-six hours after infection, neurons were replated onto polylysine plus laminin-coated glass slides for another $8 \mathrm{~h}$ in growth media. Neurons were then starved for serum and neurotrophin for $2 \mathrm{~h}$ before treatments. In all cases, after treatments as indicated in the text, SCG or hippocampal neurons were washed with cold PBS and fixed with $4 \%$ paraformaldehyde in PBS for $15 \mathrm{~min}$ at room temperature (RT). After fixation, the cells were washed two times with cold PBS and incubated in blocking solution ( $5.5 \%$ goat serum, $0.1 \%$ Triton/PBS) for $1 \mathrm{~h}$ at RT. After exposing the cells to primary antibodies diluted in blocking solution for $2 \mathrm{~h}$ at RT or overnight at $4^{\circ} \mathrm{C}$, the cells were washed three times with PBS and then probed with fluorescently labeled secondary antibodies, washed three times, and mounted on slides. Primary antibodies used were the following: rabbit anti-P-Erk5 (1:500; Biosource, Camarillo, CA), anti-HA (1:200; Santa Cruz Biotechnology), rabbit antiP-Trk (1:100; Cell Signaling Technology, Beverly, MA), rabbit anti-TrkB (1:200) (Fryer et al., 1996), rabbit anti-Pincher (1:1000) (Shao et al., 2002), and mouse mAb anti-dynamin (1:250; Transduction Laboratories, Lexington, KY). The fluorophore-conjugated secondary antibodies used in this study were the following: goat anti-mouse Alexa 488/Alexa 546 or goat anti-rabbit-Alexa 488/Alexa 546 (Molecular Probes), goat anti-rabbit-cyanine 5 (Cy5), or goat anti-mouse-Cy5 (Jackson ImmunoResearch, West Grove, PA). All images were obtained using an LSM 510 laser scanning confocal microscope (Zeiss, Oberkochen, Germany). To avoid bleed-through, fluorophores were activated and signal captured sequentially using the following filters: 505-530/GFP/Alexa488, 560610/Alexa546, and LP 650/Cy5.

Neuronal survival. Sympathetic neurons were cultured in compartmentalized chambers as described previously (Tsui-Pierchala and Ginty, 1999). Eight to $10 \mathrm{~d}$ after plating, the cells were infected with LacZ, GFP, HA-Pincher, HA-G68Epincher, and dynaminK44A viruses in growth medium consisting of $1 \%$ FBS for $8 \mathrm{~h}$. After washing the cells three times with DMEM, the cell bodies were kept in 1\% FBS medium, and the distal axons were maintained in 10\% FBS. The cell bodies and distal axon compartments were treated with 10 ng of NGF or anti-NGF (1:1000; Sigma), as indicated in the figure legends. To score projecting cell bodies in the survival assay, $40 \mathrm{~nm}$ fluorescent microspheres (1:500; Molecular Probes) were added to distal axon compartments. Seventy-two hours after infections, the cells were fixed in $4 \%$ paraformaldehyde at room temperature for $15 \mathrm{~min}$. Detection of cells expressing HA-Pincher, HAG68Epincher, and dynaminK44A was performed as described above. The nucleus was stained with 4',6-diamidino-2-phenylindole (1:1000; Vector Laboratories, Burlingame, CA) at room temperature for $5 \mathrm{~min}$. A cell with a condensed, fragmented, or with no nucleus was scored as apoptotic.

Electron microscopy and immunogold labeling. SCG and hippocampal neurons were plated on collagen and poly-D-lysine-coated ACLAR film (Ted Pella, Redding, CA), respectively, and cultured as described above. Immunogold electron microscopy (EM) was performed as described for PC12 cells (Shao et al., 2002), except that cells were microwave fixed for $30 \mathrm{~s}$ at $650 \mathrm{~W}$ using a Pelco3451 microwave (Ted Pella) in a cold mixture of $2 \%$ paraformaldehyde and $0.05 \%$ glutaraldehyde in $0.1 \mathrm{M}$ phosphate buffer, $\mathrm{pH}$ 7.4. To detect TrkB-GFP and Pincher, we used rabbit antiGFP (1:20,000; Molecular Probes or 1:6000; Eusera, Edmonton, Alberta, Canada) and rabbit anti-Pincher (1:50,000), respectively, on ultrathin sections of Durcapan-embedded cells.

Image processing and quantitative analysis. All fluorescence images were digitally analyzed using Aim 3.2 software (Zeiss) and processed using Photoshop (Adobe Systems, San Jose, CA). The weighted colocalization coefficient, defined as the sum of intensities of colocalizing pixels for Pincher or P-TrkA compared with the overall sum of pixel intensities (above threshold) for Pincher or P-TrkA, was determined. This was calculated using the Aim 3.2 colocalization macro (Zeiss) according to Manders et al. (1993), which gives a higher value to brighter pixels.

Unless otherwise indicated, statistical analyses on quantified experiments were performed using the Mantel-Haenszal $(\mathrm{M}-\mathrm{H})$ test for equal rates (odds ratio of 1.0)

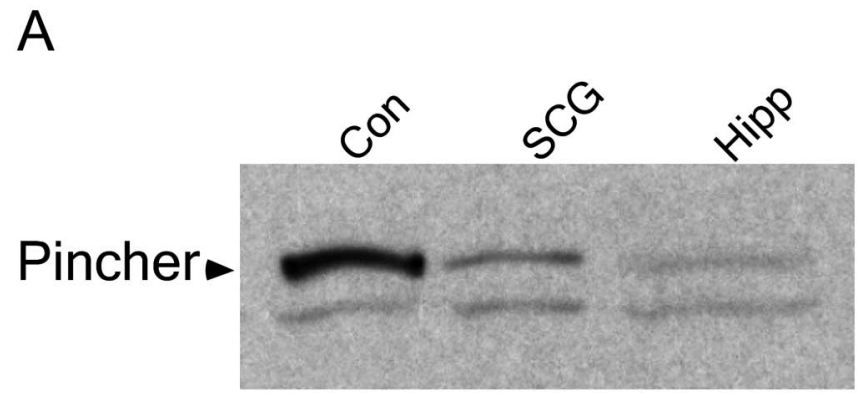

B

\section{RT-PCR: Cycle Threshold Pincher GAPDH SCG $\quad 22.3 \pm 0.12 \quad 16.7 \pm 0.09$ Hipp $\quad 24.1 \pm 0.23 \quad 16.9 \pm 0.18$}

Figure 1. Pincher is expressed in peripheral and central neurons. Pincher expression in SCG neurons (SCG) and hippocampus (Hipp) was determined by Western blot of whole-cell extracts probed with anti-Pincher antibody for protein $(\boldsymbol{A})$ and by quantitative reverse transcription- $P C R$ for mRNA (B), as described in Materials and Methods. $\boldsymbol{A}$, Control lane (Con) identifies Pincher band (compared with band for other Pincher family member below) that is increased in SCG neurons infected with adenovirus driving Pincher expression. $\boldsymbol{B}$, In reverse transcription-PCR, the cycle threshold for Pincher is compared with that for the standard GAPDH.

\section{Results}

Pincher mediates TrkA internalization and endosomal Erk5 signaling in neurons

Expression of Pincher in sympathetic neurons of the SCG was determined by Western blot analysis (Fig. 1A). Two immunoreactive species were observed of apparent sizes of $68 \mathrm{kDa}$ (major) and $65 \mathrm{kDa}$ (minor), corresponding to the sizes of Pincher (Shao et al., 2002) and the highly homologous Pincher family members, rEHD1/2 (Mintz et al., 1999; Guilherme et al., 2004), respectively. The $68 \mathrm{kDa}$ protein was positively identified as Pincher in SCG neurons overexpressing an HA-tagged Pincher cDNA (Fig. $1 A$ ). The expression of Pincher in SCG neurons was also confirmed by reverse transcription-PCR using primers specific for the $3^{\prime}$ untranslated region of Pincher mRNA in glia-depleted primary cultures of SCG neurons (Fig. $1 B$ ).

Localization of Pincher and TrkA in SCG neurons was examined after cotransfection with mammalian expression vectors containing either an HA-tagged Pincher or TrkA. These proteins were detected by confocal immunofluorescence microscopy using antibodies directed against phospho-Y490-TrkA (for active P-TrkA) and HA (for HA-Pincher). Two distributions of Pincher and P-TrkA were observed (Fig. $2 \mathrm{~A}$ ), each of which is consistent with Pincher involvement in TrkA endocytosis. First, Pincher and P-TrkA were often colocalized at discrete foci along the plasma membrane and at numerous cytoplasmic endosome-like foci, particularly at short times after NGF treatment after starvation (weighted colocalization coefficient for P-TrkA, 70\%; HAPincher, 60\%) (Fig. 2A, top). Second, in cells in which cytoplasmic P-TrkA foci accumulated extensively, Pincher and P-TrkA were differentially distributed. In this situation, Pincher was found predominantly in tubular structures surrounding pronounced accumulations of cytoplasmic P-TrkA foci and on the 
A

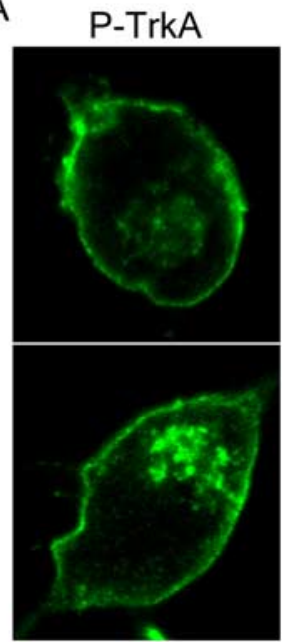

B
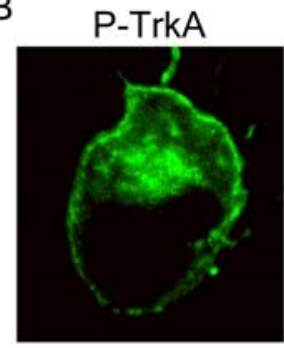

C

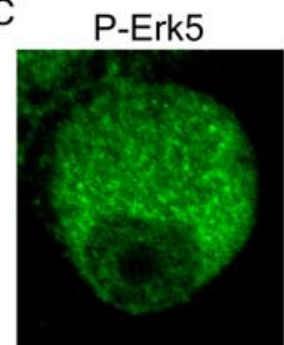

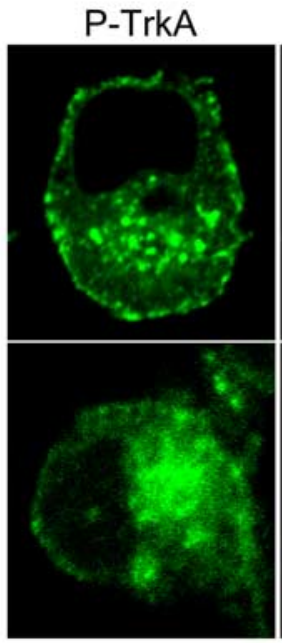

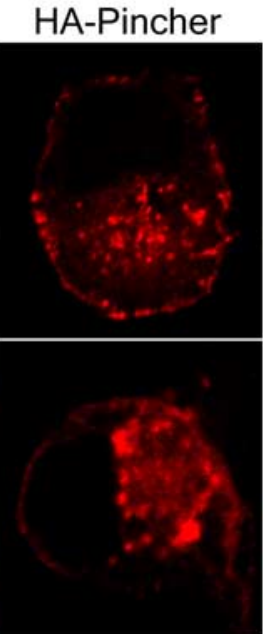

P-TrkA

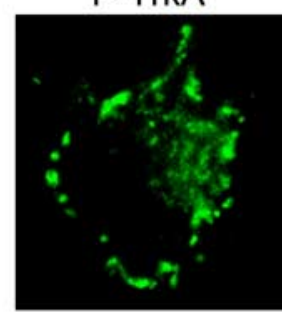

HA-PinG68E
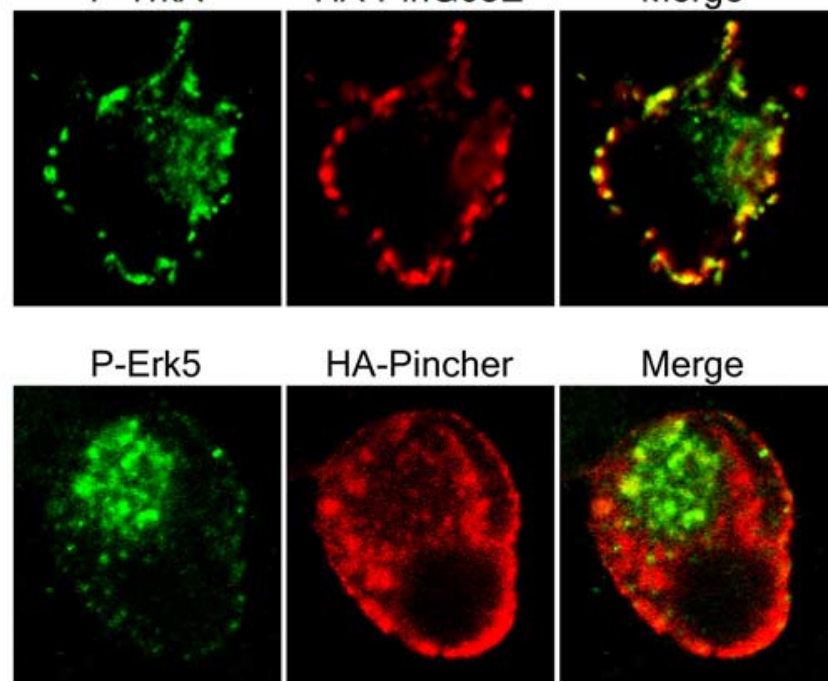

Figure 2. Pincher mediates formation of TrkA-signaling endosomes that associate with active Erk5 kinase in SCG neurons. Cultured SCG neurons were transfected with a TrkA construct alone $(A, B$, left) or infected with a HA-Pincher-containing adenovirus alone $(\boldsymbol{C})$ or together with TrkA transfection $(\boldsymbol{A}$, right) or were infected with dominant-negative mutant HA-PincherG68Econtaining adenovirus together with TrkA transfection ( $\boldsymbol{B}$, right) or uninfected ( $\boldsymbol{C}$, left). Neurons were then treated with NGF for 15 $\min (\boldsymbol{A}$, top row, $\boldsymbol{C}$ or continuously $(\boldsymbol{A}$, bottom row, $\boldsymbol{B})$, fixed, stained, and confocal microscopy was performed as described in Materials and Methods. Active, P-TrkA (green; $\boldsymbol{A}, \boldsymbol{B}$ ), HA-Pincher (red; $\boldsymbol{A}, \boldsymbol{C}$ ), HA-PincherG68E (HA-PinG68E; $\boldsymbol{B}$ ), and P-Erk5 (green; $\boldsymbol{C}$ ) were visualized using anti-P-TrkA, anti-HA, and anti-P-Erk5 antibodies, respectively. Scale bar: (in $\boldsymbol{A}$ ) $2 \mu \mathrm{m}$.
If endogenous Pincher function is required for TrkA internalization in SCG neurons, a dominant-negative mutant form of Pincher (G68E), which blocks TrkA internalization in PC12 cells (Shao et al., 2002), should result in a reduction of cytoplasmic P-TrkA staining. Indeed, cytoplasmic accumulations of active P-TrkA were found in only $11 \%$ (from three independent experiments) of cells $(n=95)$ expressing PincherG68E compared with $67 \%$ in control uninfected cells $(n=176$; $p<0.0001)$. Moreover, a punctate distribution of P-TrkA was observed that was primarily limited to the plasma membrane and colocalized with the mutant PincherG68E (Fig. 2B). In addition, internalization of endogenous TrkA was prevented by expression of Pincher-specific RNA interference (RNAi), which resulted in elimination of HA-Pincher expression (Fig. 3A) and downregulation of endogenous Pincher protein (by 61 and $65 \%$ in two independent experiments) (Fig. $3 A$ ). Adenovirus-driven expression of Pincher RNAi in PC12 cells resulted in increased accumulation of endogenous TrkA at the cell surface by $1.5 \pm 0.06$-fold (from three independent experiments). NGF treatment caused a $50 \%$ reduction in surface TrkA in control cells as a result of internalization, which was significantly inhibited (by $60 \%$ ) as a result of Pincher RNAi expression (only $20 \%$ reduction of surface TrkA). Thus, the amount of surface TrkA in NGF-treated cells was $2.6 \pm 0.76$-fold (from three independent experiments) higher in Pincher RNAi-expressing cells (Fig. $3 B$ ), with a corresponding reduction in the percentage of the biotinylated cellsurface TrkA that was found in the internalized compartment after NGF treatment (2.8- and 1.9-fold reduction, respectively, from two independent experiments) (Fig. 3C). A similarly enhanced accumulation plasma membrane (Fig. 2A, bottom). These distributions are consistent with Pincher sorting from P-TrkA endosomes and recycling back to the plasma membrane (Shao et al., 2002).

The activated Erk5 kinase (P-Erk5) mediates downstream events of TrkA and is a critical component of endosomal Trk signaling (Watson et al., 2001; Shao et al., 2002; Geetha and Wooten, 2003). To confirm that P-Erk5 is recruited by Pincher-Trk endosomes, its distribution was examined after Pincher overexpression. Large punctate accumulations of P-Erk 5 were distributed in the cytoplasm, surrounded by Pincher (Fig. 2C) in a manner similar to that seen above for P-TrkA. In three independent experiments, cytoplasmic accumulations of P-Erk5 foci (Fig. 2C) were observed in $66 \%$ of cells $(n=264)$ overexpressing Pincher compared with only $5 \%$ in control cells $(n=401 ; p<0.0001)$. Extensive colocalization of cytoplasmic yellow fluorescent protein-TrkA and P-Erk5 was observed (data not shown), substantiating the conclusion that P-Erk5 is recruited to the Trk endosomes.
(1.8 \pm 0.33 -fold, from three independent experiments) of cellsurface TrkA was seen in NGF-treated SCG neurons infected with Pincher RNAi virus (Fig. 3D). Pincher RNAi expression caused no change in total cellular Trk levels in PC12 cells or sympathetic neurons (Fig. $3 B-D$ ). These effects were specific for Pincher RNAi, because no effects on either Pincher expression or TrkA internalization were seen with expression of RNAi that was instead specific for other Pincher family members (data not shown).

Pincher effects on Trk endocytosis are not restricted to NGF, TrkA, or peripheral neurons

Pincher would be expected to mediate a similar process of endocytosis of other NT/Trk family members. Thus, the endocytic profiles of TrkB and Pincher were examined in primary cultures of SCG neurons double infected with TrkB-GFP and HAPincher adenoviruses. Similar to P-TrkA, two intracellular distributions of activated P-TrkB and Pincher were observed after 
A

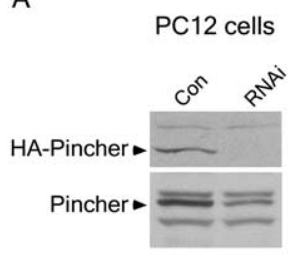

B

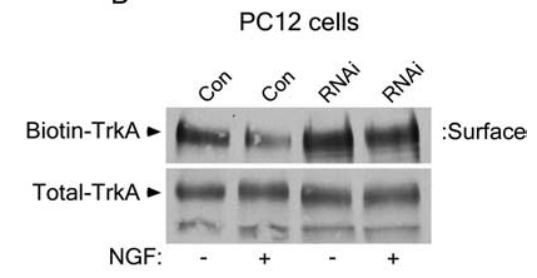

C
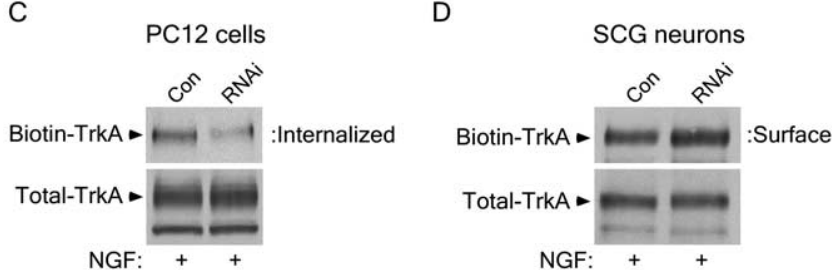

Figure 3. RNAi-mediated repression of Pincher expression retards TrkA internalization. $\boldsymbol{A}$, The ability of Pincher-specific RNAi to block Pincher protein expression was determined in cell extracts taken from $\mathrm{PC} 12$ cells transfected with a $\mathrm{HA}-\mathrm{Pincher}$ (Con) construct alone or together with a Pincher-RNAi (RNAi) construct using Western blots probed with anti-HA antibody (top). Levels of endogenous Pincher probed using anti-Pincher antibody was decreased after infection with adenovirus driving Pincher-RNAi (bottom). The band corresponding to Pincher was identified by its increased intensity (compared with other Pincher family members), seen after infection of cells with adenovirus driving HA-Pincher expression, as in Figure $1 A$ (data not shown). $\boldsymbol{B}$, Internalization of TrkA was compared between control and Pincher-RNAiexpressing PC12 cells. After NGF treatments as indicated, cell-surface TrkA was biotinylated, immunoprecipitated, and identified by Western blot using anti-TrkA antibody, as described in Materials and Methods. Equal amounts of PC12 extract proteins were loaded in each lane. C, The effects of Pincher-RNAi expression on internalized surface TrkA were directly assessed in PC12 cells. Cells were surface biotinylated, treated with NGF, then debiotinylated as described in Materials and Methods. The remaining biotinylated (internalized) TrkA was detected as in B.D. The effects of Pincher-RNAi expression on internalization of surface TrkA was determined in SCG neurons. NGF-treated neurons were infected, surface biotinylated, and TrkA was detected as in $\boldsymbol{B}$. $\beta$-Tubulin, probed for in the same blot as the SCG extracts (data not shown), was used to control for protein loading. Total TrkA protein was determined from the same PC12 cell and SCG extracts used to measure surface TrkA internalization. Con, Control.

BDNF treatment. First, Pincher and P-TrkB colocalized at cytoplasmic foci (Fig. $4 A$, top). Second, Pincher was found in tubular structures that surrounded cytoplasmic accumulations of P-TrkB foci (Fig. 4A, bottom). When TrkB-GFP was expressed together with dominant-negative HA-PincherG68E, a nearly complete inhibition of P-TrkB internalization was observed. $\mathrm{P}-$ TrkB and PincherG68E were instead colocalized in large puncti along the plasma membrane (Fig. $4 B$ ).

TrkB is expressed in both peripheral and central neurons, in which it mediates events leading to neuronal survival and plasticity. Both Pincher mRNA and protein are expressed in the hippocampus of E18 rats (Fig. $1 A$ ), which is nearly devoid of glia (Maher et al., 1999). Although they normally express TrkB, cultured hippocampal neurons do not require neurotrophins for their survival. Thus, permitting growth in media lacking BDNF provided an opportunity to examine the roles of the Trk ligand as well as Pincher in mediating endocytosis and Trk endosomal signaling. In neurons expressing TrkB-GFP, significant levels of $\mathrm{P}$-TrkB were seen in cytoplasmic foci resembling endosomal structures (data not shown). In the absence of BDNF ligand, 36\% (from three independent experiments) of infected cells $(n=90)$ contained cytoplasmic accumulations of P-TrkB, indicating that in cells overexpressing TrkB, significant activation and internalization of TrkB occurs. As expected, when TrkB-GFP-expressing cells were treated with BDNF for $30 \mathrm{~min}$, increased staining of both plasma membrane and endocytosed P-TrkB was observed, and the number of cells ( $n=94)$ with cytoplasmic accumulations was greatly increased to $68 \%(p<0.0001)$. The ability of Pincher to mediate internalization of $\mathrm{P}-\mathrm{TrkB}$ was examined in hippocampal neurons coinfected with adenoviruses harboring TrkB-GFP or HA-Pincher and treated with BDNF. The distribution of Pincher and P-TrkB was similar to that seen in sympathetic neurons, with colocalization at both plasma membrane and cytoplasmic foci (Fig. 4C, top) or Pincher surrounding cytoplasmic accumulations of P-TrkB endosomes (Fig. 4C, bottom). Even in the absence of BDNF, the extent of cytoplasmic accumulation of active P-TrkB $(62 \% ; n=213$ from three independent experiments) was greatly increased by coexpression of Pincher $(p<0.0001)$. Importantly, as in sympathetic neurons, endocytosis of activated TrkB in hippocampal neurons depended on Pincher function. Coexpression of dominant-negative mutant PincherG68E resulted in the codistribution of P-TrkB with PincherG68E at large puncti, restricted to the plasma membrane (Fig. 4D).

In neurons, neurotrophins are internalized after binding to both p75 and Trk receptors. To determine whether signaling through TrkB (but not p75) was sufficient for Pincher-mediated internalization, a chimeric protein was introduced that contains the extracellular domain of EGF receptor fused to the transmembrane and cytoplasmic domains of TrkB (EGFR/TrkB). This chimeric receptor binds to EGF, but the signaling pathways are mediated by TrkB (Wang et al., 1996). Cultured hippocampal neurons were transfected with the EGFR/TrkB construct and infected with adenovirus harboring HA-Pincher. The neurons were then exposed to fluorescently tagged EGF (EGF-Alexa555) to monitor internalized EGF, followed by staining with anti-HA and anti-P-TrkB antibodies. As shown in Figure 4E, EGF was found together with P-TrkB in cytoplasmic accumulations surrounded by tubulo-vesicular arrays of HA-Pincher, thus demonstrating that Pincher-mediated endocytosis of ligand-Trk complexes is not dependent on ligand binding to p75.

\section{Pincher mediates a novel process of Trk macroendocytosis}

To gain insight into both the nature and the mode of formation of TrkB and Pincher-containing structures, they were ultrastructurally characterized by immunogold electron microscopy. To circumvent an incompatability of available anti-TrkB antibodies and their visualization with high-quality ultrastructure, we used neurons expressing TrkB-GFP and HA-Pincher and analyzed them using anti-GFP (for TrkB-GFP) and anti-Pincher (for HAPincher) antibodies. As expected, when TrkB-GFP was expressed, it could be seen associated with cytoplasmic endoplasmic reticulum (ER) (data not shown). In neurons, TrkB-GFP and HA-Pincher were associated with four endocytic structural arrangements as exemplified in Figure 5. In the first arrangement, both TrkB-GFP (Fig. 5A, top) and HA-Pincher (data not shown) were concentrated at typical membrane ruffles that appeared as plasma membrane loops in ultra-thin sections. Although gold labeling for both TrkB-GFP and HA-Pincher could also be seen sporadically all along the plasma membrane, neither was seen associated with clathrin-coated pits (data not shown). TrkB-GFP and HA-Pincher were primarily coconcentrated at complex cellsurface ruffles that encompassed accumulated pinocytic vesicles of varied sizes, as seen by gold labeling for both proteins in serial thin sections (Fig. 5A, second panel). Varying the relative expression levels of TrkB-GFP and HA-Pincher indicated that with more Pincher, the vesicular structures within ruffles were more evenly sized and in a more ordered arrangement (data not shown). TrkB-GFP and HA-Pincher were additionally coconcentrated in a distinctive structural arrangement in the cytoplasm 
A
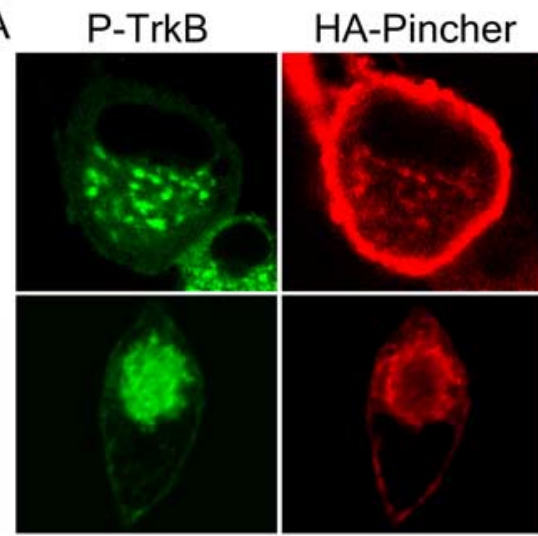

B

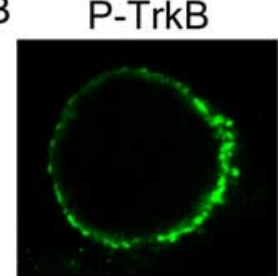

C
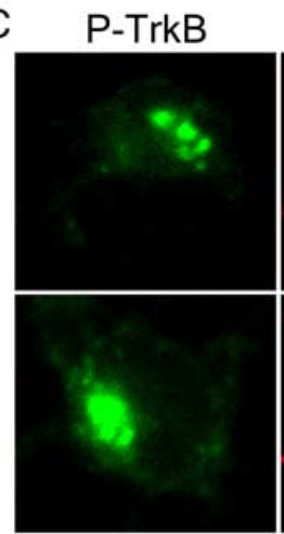

D

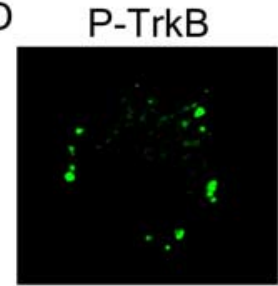

E

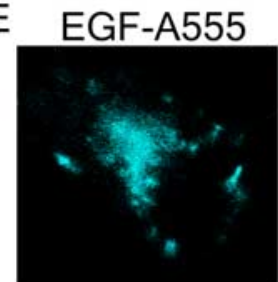

HA-PinG68E

HA-Pincher

HA-PinG68E
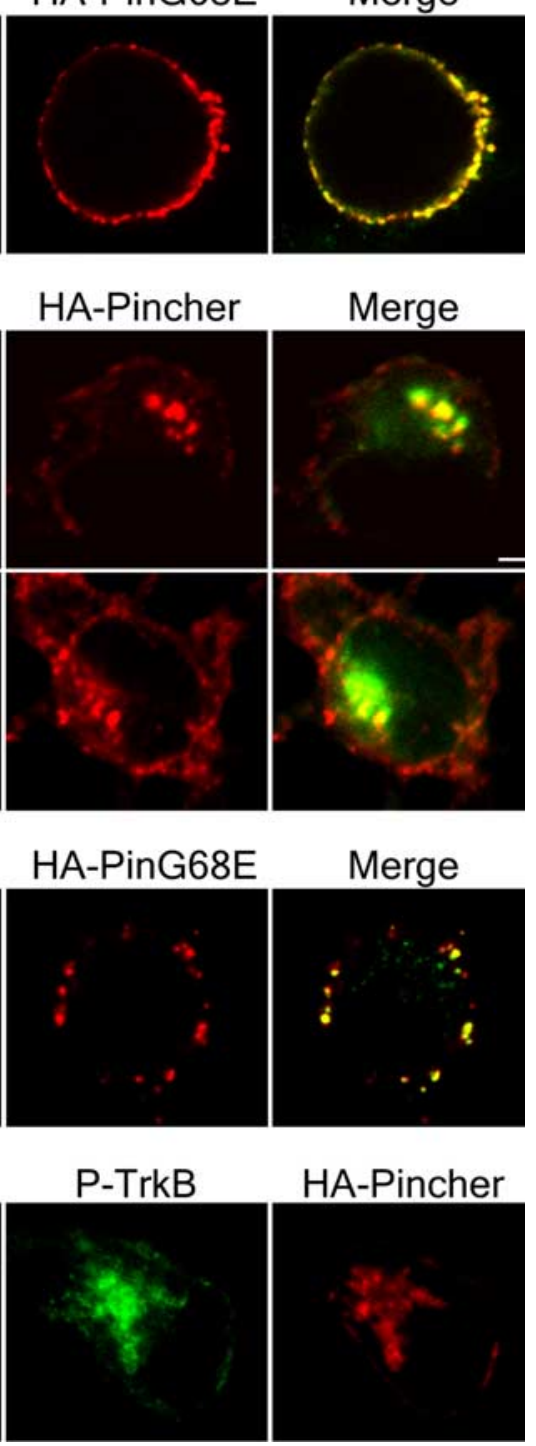

Figure 4. Pincher mediates endocytosis of ligand-bound TrkB in SCG and hippocampal neurons. Cultured SCG $(\boldsymbol{A}, \boldsymbol{B})$ or hippocampal $(\boldsymbol{C}-\boldsymbol{E})$ neurons were double infected with adenoviruses containing TrkB-GFP or HA-Pincher $(\boldsymbol{A}, \boldsymbol{C})$, TrkB-GFP or HA-PincherG68E $(\boldsymbol{B}, \boldsymbol{D})$, an EGFR/TrkB chimera (with extracellular domain of EGFR and transmembrane with intracellular domains of TrkB or HA-Pincher; $\boldsymbol{E})$. Neurons were treated with BDNF for $15 \min (\boldsymbol{A}, \boldsymbol{C}$, top) or $1 \mathrm{~h}$ $(\boldsymbol{A}-\boldsymbol{C}$, bottom, $\boldsymbol{D})$ or treated for 15 min with EGF coupled to Alexa555 $(\boldsymbol{E})$. Neurons were fixed and stained as in Figure 2 for P-TrkB (green; $\boldsymbol{A}-\boldsymbol{E}$ ), HA-Pincher (red; $\boldsymbol{A}, \boldsymbol{C}, \boldsymbol{E}$ ), HA-PincherG68E (HA-PinG68E; red; $\boldsymbol{B}, \boldsymbol{D})$, and EGF-Alexa555 (blue; EGF-A555; $\boldsymbol{E}$ ), which were visualized directly. Scale bar: (in $C) 2 \mu \mathrm{m}$. at what appeared to be internalized complex pinocytic membrane ruffles, which we termed macroendosomes. The same macroendosomal structures were gold labeled for both TrkB-GFP and HA-Pincher as seen in serial thin sections (Fig. 5A, third panel), suggesting that $\operatorname{TrkB}$ and Pincher are coendocytosed within these structures. In the fourth structural arrangement, TrkB-GFP and HA-Pincher were seen in accumulations of multivesicular bodies (MVBs). Gold-labeled TrkB-GFP was found preferentially in internal vesicles of the MVBs but was also present at the outer membrane (Fig. 5A, bottom). The same MVBs often contained gold-labeled HA-Pincher along the outer endosomal membrane. Compared with the distribution of labeled TrkB-GFP, gold-labeled HA-Pincher was rarely found in the internal vesicles, as shown in labeled serial sections (Fig. $5 \mathrm{~A}$, fourth panel).

Trk-Pincher MVBs appeared to be formed directly from the macroendosomes, because intermediates in this process were observed. In TrkB-GFP- (Fig. 5B, right) and/or HA-Pincher- (Fig. $5 B$, left) expressing neurons, gold-labeled structures were observed in the cytoplasm that appeared to contain macroendosomes that were contiguous with multivesicular body-like structures, suggesting intermediates in endosome formation and processing. As expected, gold-labeled TrkB-GFP was associated with both macroendosomal and multivesicular body-like structures, whereas gold-labeled HA-Pincher was primarily associated with the macroendosomal areas of the intermediates. As reported previously (Shao et al., 2002), HA-Pincher-expressing cells also contained putative recycling structures consisting of large Pincher-labeled tubules throughout the cytoplasm (data not shown), suggesting that after processing of macroendosomes to MVBs, excess Pincher is recycled to the plasma membrane.

Increased expression of TrkB-GFP and/or Pincher modulated endosomal processing. In neurons expressing TrkB-GFP, macroendosomes as well as MVBs (and the ER) were more numerous, and the MVBs were more often vesicle filled than those seen in control-infected neurons (Fig. 6, Table 1), suggesting that increased expression of Trk drove more endosome formation and maturation. Many more of the gold-labeled MVBs were also electron dense in TrkB-GFP-overexpressing neurons (Fig. 6, Table 1), indicative of increased lysosomal processing with Trk overexpression. Overexpression of HA-Pincher alone also caused an enhanced accumulation (approximately threefold) of MVBs, but these were much larger and for the most part only partially filled and thus less mature (Fig. 6, Table 1). When HA-Pincher was coexpressed with TrkB-GFP, the number of MVBs was dramatically increased (over ninefold), but they were again only partially filled with vesicles (Fig. 6, Table 1). This result indicates that TrkB-GFP and HA-Pincher synergistically enhanced production of MVBs while keeping them unfilled. Remarkably, the endosomal MVBs seen in both the Pincher-overexpressing and the Pincher and TrkB-GFP-overexpressing neurons were almost never electron dense (Fig. 6, Table 1), regardless of the extent to which they were vesicle filled, indicating that they were refractory to lysosomal processing. These results suggested that Pincher retarded the maturation of Trk-containing MVBs, making them resistant to degradation. To more directly assess effects of Pincher overexpression on endosome-mediated Trk degradation, the degradation of endogenous cell-surface TrkA was assessed in sympathetic neurons. For this, cell-surface TrkA was biotinylated in control and HA-Pincher-overexpressing cultured SCG neurons starved for $2 \mathrm{~h}$ of NGF. After treatment with NGF for $3 \mathrm{~h}$, we observed 2.4- and 2.8-fold (from two independent experiments) more biotinylated TrkA remaining in whole-cell extracts of neu- 
rons expressing HA-Pincher compared with control cells (data not shown). Thus, increased Pincher expression conferred protection from degradation on cellsurface TrkA.

\section{Pincher-mediated Trk endocytosis is globally mediated in all neuronal compartments}

For Pincher to mediate internalization of Trk in axons and axon terminals, it must be expressed there. To visualize Pincher distribution along axons, primary SCG neurons were infected with an adenovirus independently driving expression of Pincher and GFP. GFP-labeled neurons were fixed and stained with anti-Pincher antibody. As seen in Figure 7A, Pincher was present in axon terminals and was highly localized to membrane ruffles. Endogenous Pincher was also present in axons as determined by Western blot analysis of the distal axon compartment of neurons grown in chamber cultures (data not shown). To determine whether Pincher mediated the internalization of Trk in axons, SCG neurons were double infected with adenoviruses driving TrkBGFP or HA-Pincher expression. As shown in Figure $7 B$, after infected neurons were treated with BDNF for $15 \mathrm{~min}$, large accumulations of colocalized TrkB and Pincher were observed predominantly at the terminal (weighted colocalization coefficient for TrkB, $0.56 \pm 0.20$; Pincher, $0.54 \pm$ $0.19 ; n=24)$, and costained puncti were also seen along the axon (Fig. $7 B$, left). The TrkB appearing at these foci was activated, because similar results were seen with antiP-Trk staining. After 1 h of BDNF treatment, large foci of colocalized P-Trk and HA-Pincher were seen along the axon (weighted colocalization coefficient for P-TrkB, $0.70 \pm 0.08$; Pincher, $0.59 \pm 0.10$; $n=22$ ) (Fig. $7 B$, right). Serial optical sections of axons and terminals indicated that many foci were axoplasmically internalized (data not shown). To determine whether Pincher is required for Trk internalization at the axon terminal, TrkB-GFP was coexpressed in SCG neurons along with the dominant-negative mutant PincherG68E. Even after BDNF treatment of these neurons, P-Trk was found to be highly colocalized with PincherG68E at discrete plasma membrane locations (Fig. 7C) and, as in the cell bodies, was not internalized.

Pincher distribution was also examined in cultured hippocampal neurons, in which axons and dendrites are distinguished by enhanced tau and MAP2 labeling, respectively (Craig and Banker, 1994).
A
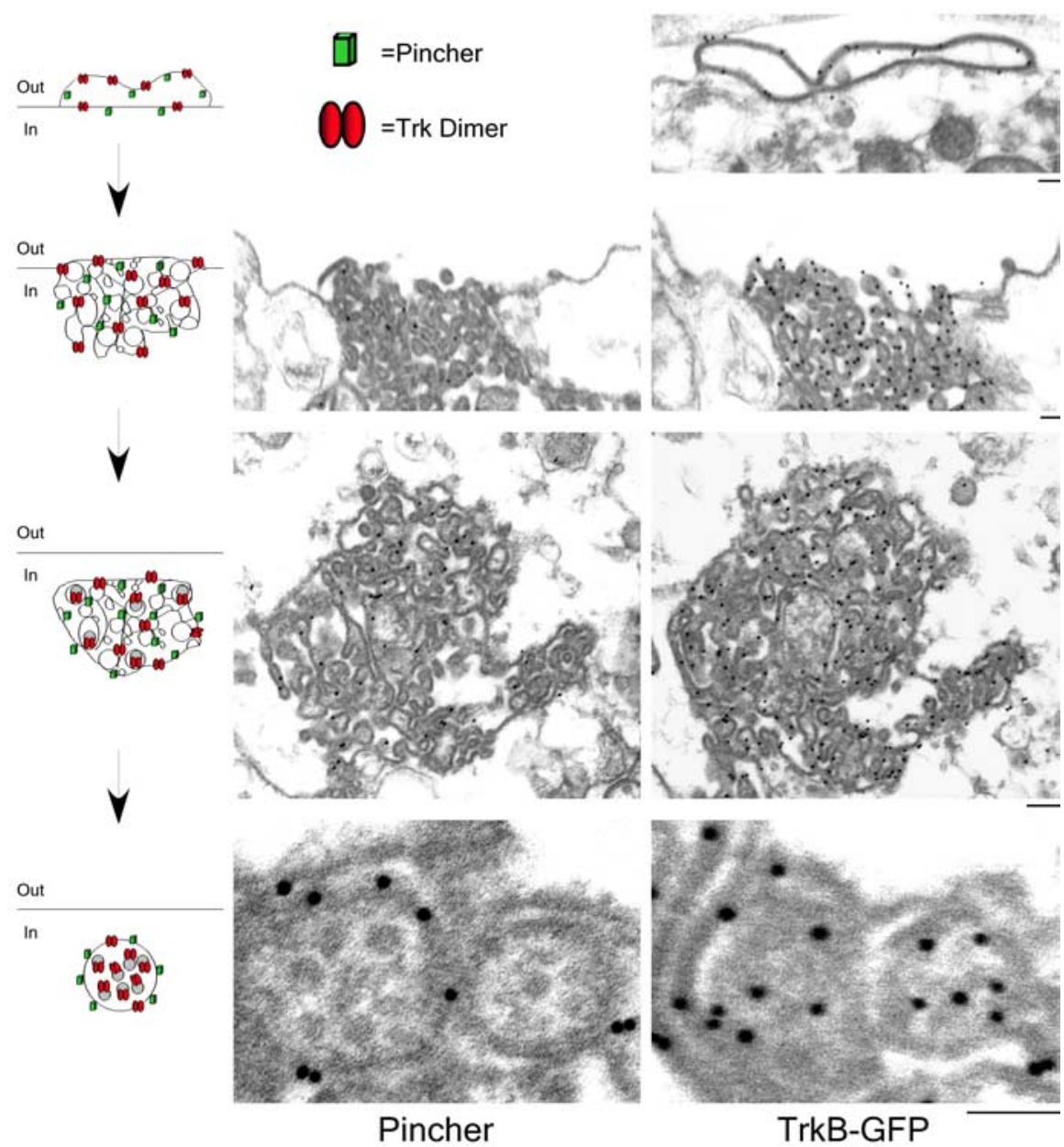

B

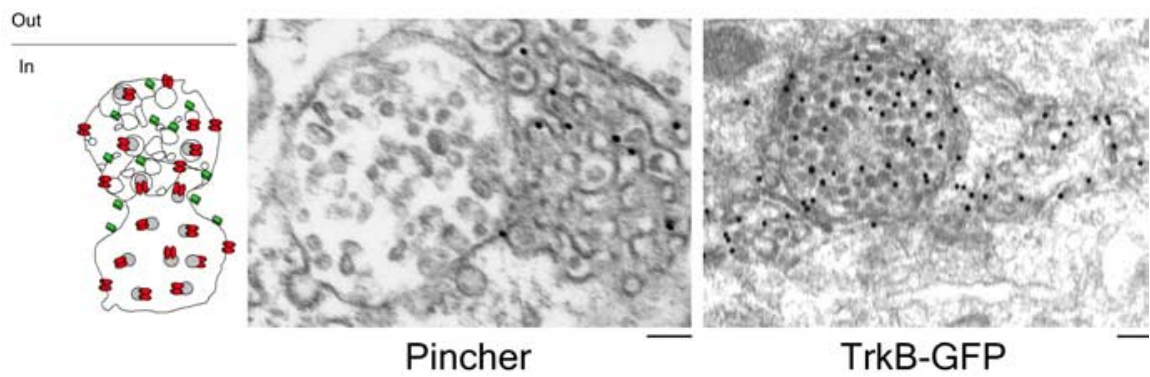

Figure 5. Ultrastructural characterization depicts stages of a novel pathway of Pincher-mediated Trk macroendocytosis. Cultured SCG neurons ( $\boldsymbol{B}$, left) or hippocampal neurons $(\boldsymbol{A}, \boldsymbol{B}$, right) were infected with adenoviruses containing TrkB-GFP $(\boldsymbol{A}$, top right, $\boldsymbol{B}$, right) or HA-Pincher ( $\boldsymbol{B}$, left) or were double infected with both viruses ( $\boldsymbol{A}, 3$ bottom panels), treated with BDNF for 30 min, and immunogold electron microscopy using anti-GFP (TrkB-GFP) or anti-Pincher (Pincher) antibodies performed as described in Materials and Methods. Immunogold-labeled TrkB-GFP and Pincher as shown in $\boldsymbol{A}$ are associated with plasma membrane ruffles (top; Pincher not shown), complex plasma membrane ruffles with pinocytic vesicles (second panel), internalized complex ruffles termed macroendosomes (third panel), and MVBs (bottom panel) as shown in the gold-labeled serial sections (second through fourth panels). All structures in $A$ are double labeled for TrkB-GFP and HA-Pincher, but only the MVBs (bottom) show sorted labeling with both on the outer membrane and only TrkB-GFP on internal vesicles. In $\boldsymbol{B}$, intermediates in which macroendosomes are fused to budding MVBs are similarly gold labeled for TrkB-GFP and HA-Pincher. Cells that were treated with BDNF at various times between 3 min and $1 \mathrm{~h}$ were analyzed by immunogold EM for Pincher and TrkB-GFP (data not shown). Only the 30 min time point was exhaustively analyzed by immunogold labeling of alternate serial sections as depicted here, which represents structures seen at all time points. The diagrams on the left side depict interpretive sequential ordering of composites gleaned from the analyses of all time points and correspond to the adjacent EM photos. Scale bars, $0.2 \mu \mathrm{m}$. 


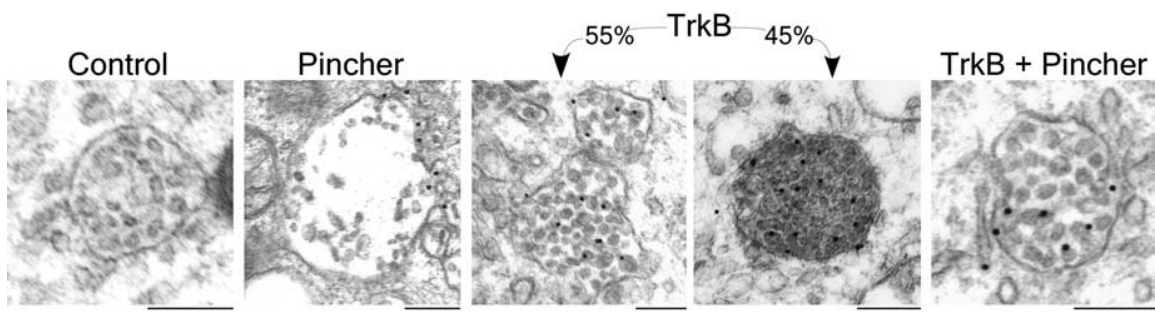

Figure 6. Pincher is associated with Trk endosomes that resist lysosomal processing. Cultured neurons were infected with adenoviruses driving expression of and immunogold EM labeled for GFP (Control), HA-Pincher (Pincher), TrkB-GFP (TrkB), or double infected with the latter two viruses (TrkB + Pincher; only TrkB-GFP labeling shown), as in Figures 4 and 5. Photomicrographs depict typical examples of MVBs in each case. Forty-five percent of the MVBs in cells expressing TrkB-GFP alone was electron dense, indicating lysosomal processing. Scale bars, $0.2 \mu \mathrm{m}$.

When these neurons were infected with adenovirus driving HAPincher expression, Pincher was found in the cell body and in all axonal and dendritic processes labeled or not for either MAP2 or tau in a similarly even punctate pattern (data not shown). In neurons expressing TrkB-GFP and HA-Pincher, colocalization of these proteins in large foci was observed regularly distributed along all processes of these neurons (weighted colocalization coefficient for TrkB-GFP, $0.81 \pm 0.07$; HA-Pincher, $0.71 \pm 0.11$; $n=10$ ) (Fig. 7D). The internalized Pincher and TrkB-GFP structures seen in virus-infected sympathetic and hippocampal axons and/or dendrites were further analyzed by immunogold electron microscopy using anti-Pincher and anti-GFP antibodies, respectively. TrkB-GFP and Pincher were seen at surface complex ruffling structures, macroendosomes, and MVBs, similar to those seen in the soma (data not shown). The existence of putative Pincher recycling tubules, abundant in the cell soma, appeared to be restricted to the proximal segment of the axonal or dendritic process, adjacent to the soma. However, ultrastructurally defined structures in axons and dendrites were scarce, probably because of the much lower levels of Trk and Pincher expression in the neuronal processes after viral infection. We were thus unable to reliably determine quantitatively the relative abundance of each type of structure.

To verify that TrkB-GFP and Pincher colabeled structures represent ligand-induced internalized receptors, endocytosis of the EGF/TrkB chimeric protein was examined. When EGFR/ TrkB expressing neurons were treated with a fluorescently tagged EGF, tagged EGF was found in puncta along with TrkB and Pincher all along the processes (Fig. 7E), as was seen for BDNFinternalized TrkB-GFP and Pincher (Fig. 7D). Low $\mathrm{pH}$ treatment of the neurons removed labeled EGF from surface receptors after cold temperature $\left(4^{\circ} \mathrm{C}\right)$ incubation (data not shown) but not after the chase at $37^{\circ} \mathrm{C}$ (Fig. $7 E$ ), indicating that the labeled EGF seen after warming was internalized.

\section{Pincher mediates NGF retrograde axonal signaling in neurons}

The above results suggest that Pincher is involved in both internalization and retrograde transport of Trk endosomes in axons. To determine whether Pincher is required for retrograde signaling, we asked whether survival, a property that depends on this event, is blocked by expression of the dominant-negative PincherG68E mutant. These studies were performed in chamber cultures in which axons extend into a biochemically separate chamber from the cell bodies, allowing differential treatments of cell bodies and distal axons (Campenot, 1982). We used a retrograde survival assay in which NGF treatment selective to the distal axons mediates neuronal survival by preventing apoptosis (Ye et al., 2003). Neurons in the chambers were infected with adenoviruses driving expression of GFP, Pincher, dominant-negative PincherG68E, or dominantnegative dynaminK44A (Zhang et al., 2000; Watson et al., 2001; Ye et al., 2003). Treatment of the distal axon chamber with NGF prevented apoptotic death of neurons expressing GFP or Pincher (Fig. 8A). However, in neurons expressing PincherG68E, NGF did not prevent cell death (Fig. $8 A$ ), similar to the effects of dynaminK44A (Fig. $8 A$ ) (Ye et al., 2003). The resulting cell death was predominantly apoptotic as evidenced by prevention with the caspase inhibitor Boc-aspartyl fluoromethyl ketone (BAF) (Fig. $8 A$ ). When NGF was added to the cell bodies of infected neurons, thus bypassing retrograde axonal signaling, apoptotic death caused by PincherG68E or dynaminK44A was, as expected, significantly reduced (Fig. 8A). However, in the case of PincherG68E, the reduction was only partial (40\% reduction for PincherG68E vs 75\% reduction for dynaminK44A), perhaps the result of a contribution by Pincher to signaling events in the soma. Because retrograde P-Erk5 signaling to the nucleus occurs via an endosomal pathway to prevent apoptosis (Watson et al., 2001), we examined the distribution of P-Erk5 in the cells bodies after expression of PincherG68E or dynaminK44A. Expression of PincherG68E resulted in accumulation of P-Erk5 that was limited to the plasma membrane in all cells examined (from three independent experiments with a total of 108 cells) (Fig. 8 B, top). In contrast, expression of dynaminK44A did not cause plasma membrane accumulation of P-Erk5 and did not prevent translo-

Table 1. Expression of Trk and Pincher affects endosomal processing of multivesicular bodies

\begin{tabular}{|c|c|c|c|c|c|c|c|}
\hline Viral infection(s) & $\mathrm{MVB} /$ cell $^{*}$ & Diameter $(\mu \mathrm{m})$ & Partial (\%) & Filled (\%) & $\mathrm{e}^{-}$dense $(\%)$ & Int. (\% gold) & Ext. (\% gold) \\
\hline GFP (control) & $1.42 \pm 0.96(31)^{a}$ & $0.24 \pm 0.07(44)^{b}$ & 93 & 7 & 0 & & \\
\hline TrkB-GFP & $3.00 \pm 1.18(14)^{a}$ & $0.27 \pm 0.10(42)^{b}$ & 3 & 52 & 45 & $88(256 / 40)^{c}$ & $12(34 / 40)^{c}$ \\
\hline TrkB-GFP plus Pincher & $13.25 \pm 11.09(4)^{a}$ & $0.27 \pm 0.08(53)^{b}$ & 92 & 6 & 2 & ND & ND \\
\hline Pincher & $4.29 \pm 2.69(7)^{a}$ & $0.49 \pm 0.16(30)^{b, * *}$ & 57 & 43 & 0 & $23(19 / 30)^{c}$ & $77(62 / 30)^{c}$ \\
\hline
\end{tabular}

The table presents data obtained from EM photomicrographs of soma from cultured SCG neurons that were single or double infected with the indicated adenoviruses as described in Materials and Methods. MVBs were scored for the characteristics indicated, as to mean number per cell (MVB/cell), mean diameter, partially filled (Partial), or completely filled (Filled) with vesicles, the proportion that was lysosomally dark or electron dense ( $\mathrm{e}^{-}$dense), and the portion of gold particles found on the internal vesicles (Int.) or on the external MVB membrane (Ext.). Comparisons were statistically evaluated using the Welch-Satterthwaite $t$ test. ND, Not determined.

$a_{n}$ value for cells.

${ }^{b} n$ value for endosomes.

'Number of gold particles/number of endosomes.

*Comparisons of values to GFP control were significant to $p<0.0001$.

**Comparison to GFP control, $p<0.0001$. 
A

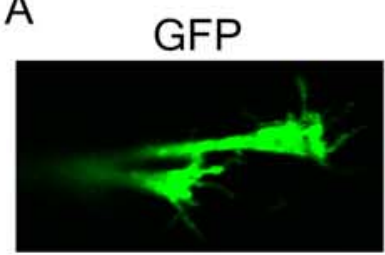

HA-Pincher

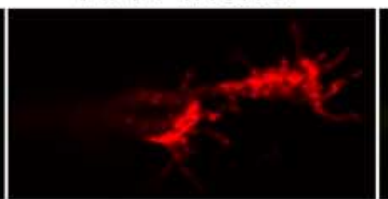

B
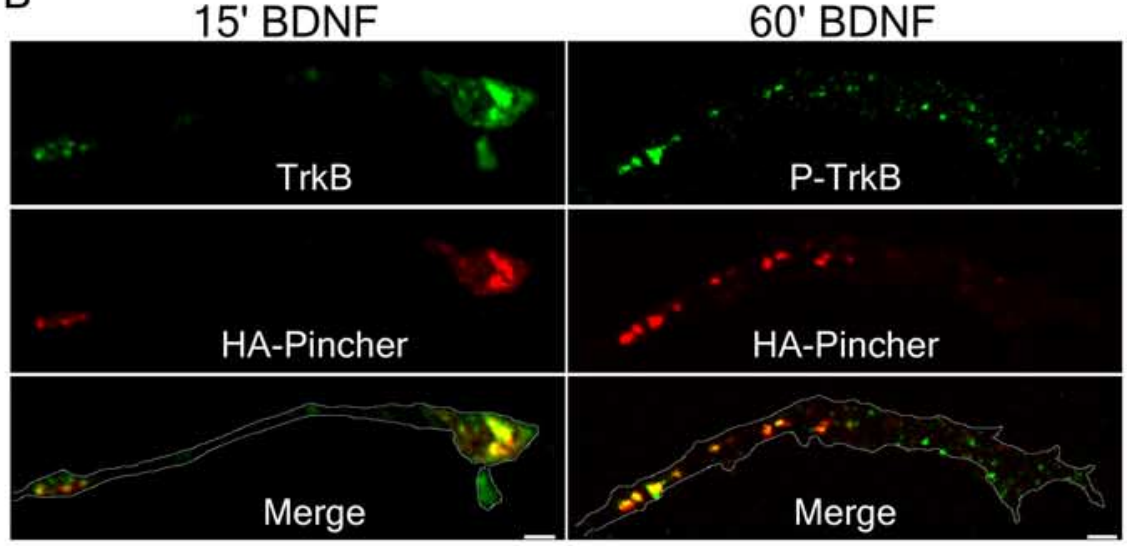

C

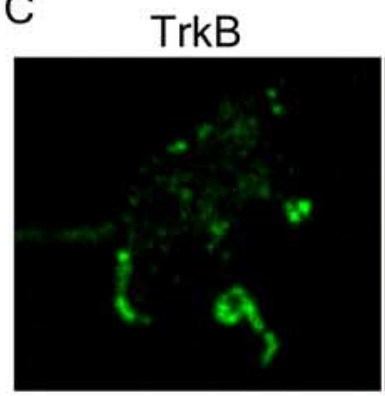

HA-PinG68E

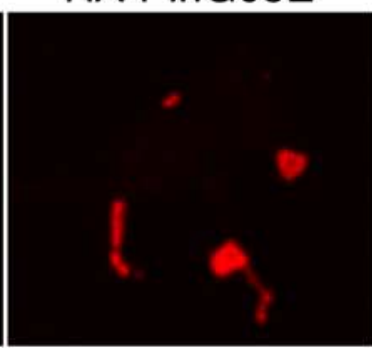

D
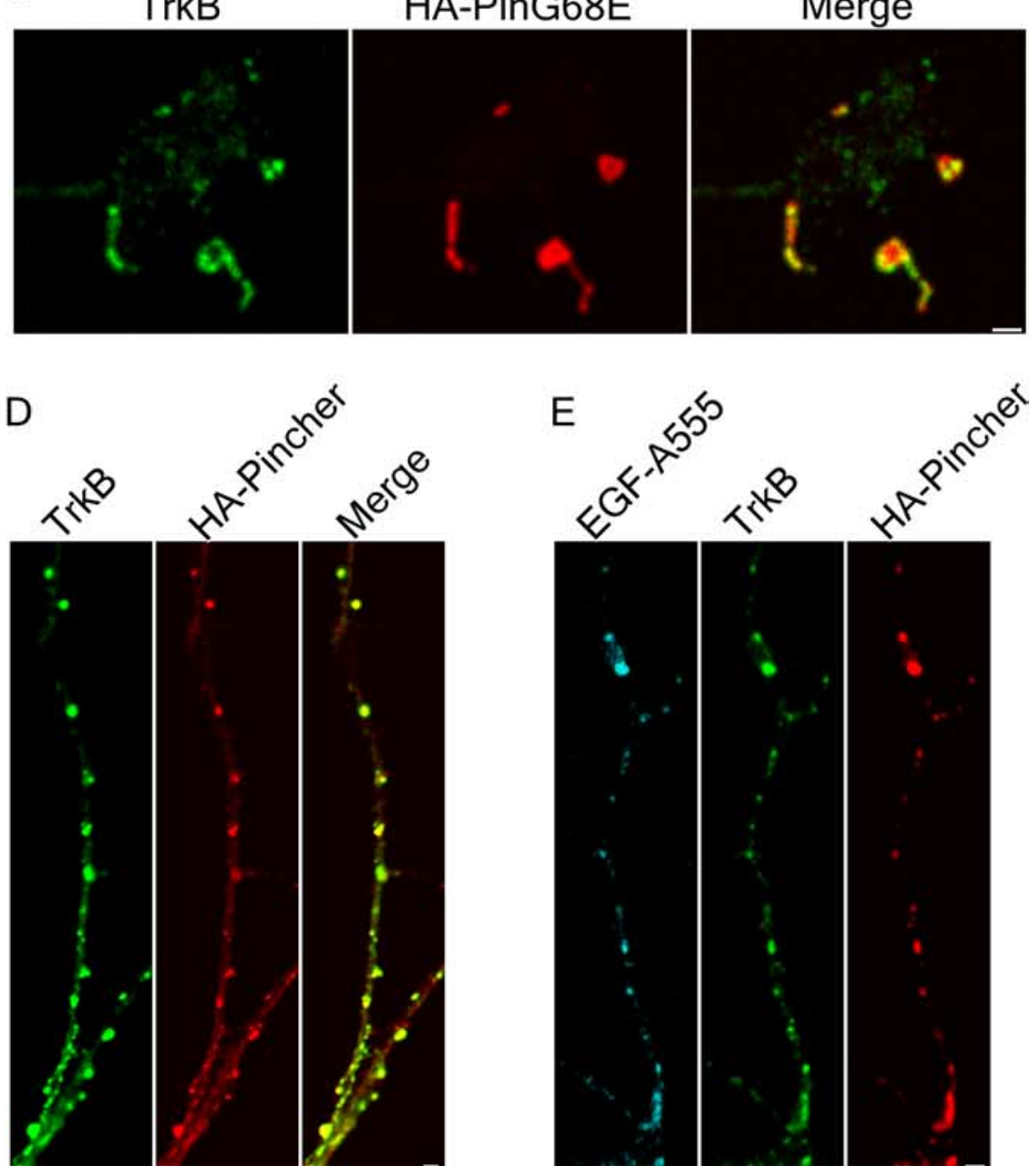

Figure 7. Pincher mediates endocytosis and trafficking of ligand-bound TrkB in axons and dendrites. Cultured SCG neurons $(\boldsymbol{A}-\boldsymbol{C})$ or hippocampal neurons $(\boldsymbol{D}, \boldsymbol{E})$ were infected with adenovirus either independently driving expression of both GFP and $\mathrm{HA}-$ Pincher $(\boldsymbol{A})$ or only HA-Pincher $(\boldsymbol{E})$ or were double infected with viruses containing TrkB-GFP together with HA-Pincher $(\boldsymbol{B}, \boldsymbol{D})$ or with cation of P-Erk 5 from the cytoplasm to the nucleus in any cells (from three independent experiments with a total of 150 cells) (Fig. $8 B$, bottom).

\section{Discussion}

Pincher-mediated endocytosis represents a unique mechanistic pathway for Trk endosomal signaling. Intermediate stages of this pathway were identified by both confocal immunofluorescence microscopy and immunogold electron microscopic analysis. Exposure of neurons to neurotrophins resulted in formation of extensive plasma membrane ruffles. Pincher and Trk were both concentrated within complex plasma membrane ruffles and cointernalized within the complex ruffles into structures termed macroendosomes. Pincher- and Trk-containing membranes were subsequently sorted from the macroendosomes to form MVBs containing Trk vesicles. This series of events is intermediate between macropinocytosis and receptor-mediated endocytosis. It is macropinocytic-like in that internalization occurs at plasma membrane ruffles that unusually encompass multiple pinocytic vesicles of varied sizes. It is endocytic-like with respect to the high concentration of Trk receptors at the site of internalization and its dependence on dynamin (G. Valdez, W. Akmentin, and S. Halegoua, unpublished observations). To reflect the shared features, we have named the Pincher-mediated process macroendocytosis.

Although Trk internalization has been suggested to occur via clathrin-mediated endocytosis (Howe et al., 2001; Heerssen et al., 2004), we have not observed Trk or Pincher associated with clathrin-coated pits or vesicles. Although it is possible that both clathrin-dependent and -independent processes each contribute to the formation of Trk endosomes, the macroendocytic process driven by Pincher represents the primary mode of activated Trk endocytosis in neurons. This was evident by the prevalence of Trk macroendosomal structures in neurons overexpressing Trk and the ability of dominant-

\footnotetext{
$\leftarrow$

HA-PincherG68E (HA-PinG68E; C). EGFR/TrkB construct was transfected into $\mathrm{HA}$-Pincher-expressing neurons $(\boldsymbol{E})$. SCG axonal processes with growth cones $(\boldsymbol{A}-\boldsymbol{C})$ and hippocampal processes $(\boldsymbol{D}, \boldsymbol{E})$ were visualized (P-TrkB, green; HA-Pincher, red) after fixation and staining as in Figure 4, except that surface-bound EGF-Alexa555 (blue) was removed by acidsalt wash before fixation, TrkB (green) was seen using antiTrkB in antibody, and GFP (green) was visualized directly, all as described in Materials and Methods. In $\boldsymbol{B}$, the axon and growth cone were outlined in the Merge to depict the location of the limiting plasma membrane. Scale bars, $2 \mu \mathrm{m}$.
} 
A

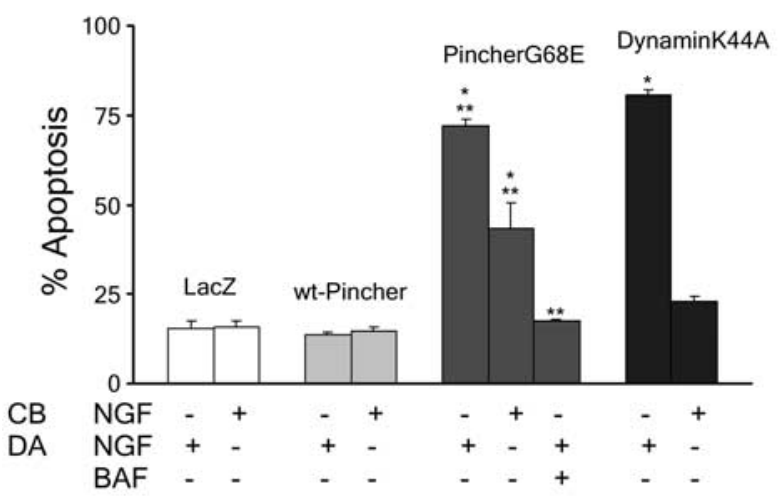

B

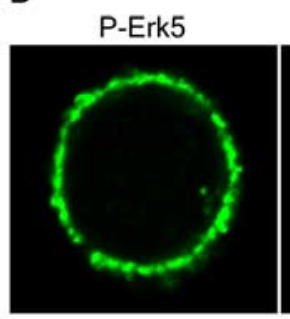
HA-PincherG68E
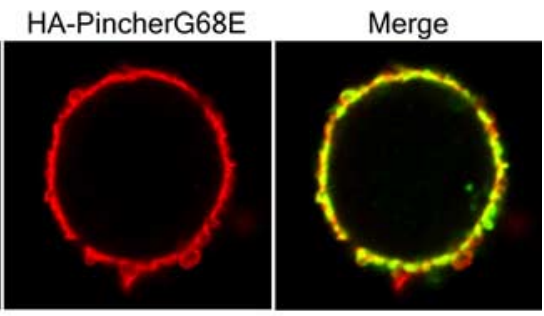

\section{P-Erk5}
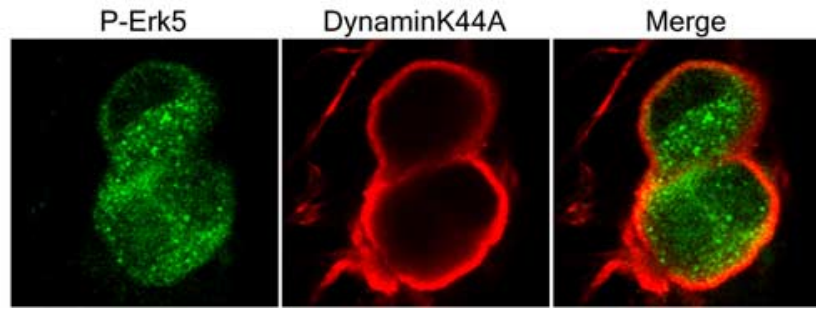

Figure 8. Pincher and dynamin mediate NGF retrograde axonal signaling, but Pincher selectively recruits P-Erk5. $A$, SCG neurons, cultured in compartmentalized chambers ( $C B$, cell body; $D A$, distal axon) for 7-9 d, were infected with viruses driving expression of LacZ, HA-Pincher, HA-PincherG68E, or dynaminK44A. The neurons were then subjected to treatment with NGF and/or BAF (caspase inhibitor) for $72 \mathrm{~h}$, as indicated. Infected neurons were visualized by staining for LacZ, HA (Pincher) antibody, and dynamin (K44A) antibody, and apoptosis was assessed as described in Materials and Methods. Values are derived from the average of three independent experiments (error bars indicate SDs). Comparative values were statistically assessed using the $\mathrm{M}$-H test. Comparisons of values between wild-type Pincher (wt-Pincher) and LacZ controls were not statistically significant ( $p>0.2$ ). Asterisks indicate comparisons to LacZ with a $p<$ 0.0001. Double asterisks indicate differences among PincherG68E values with $p<0.0001$. In the total absence of added NGF, all virally infected neurons (expressing LacZ, wt-Pincher, PincherG68E, or dynaminK44A) died (data not shown). B, SCG neurons cultured in the continuous presence of NGF were infected for $2 \mathrm{~d}$ with viruses containing $\mathrm{HA}$-PincherG68E and dynaminK44A. Active P-Erk5 (green), HA-PincherG68E (red; top), and dynaminK44A (red; bottom) were visualized using anti-P-Erk5, anti-HA, and anti-dynamin antibodies, respectively.

negative mutant PincherG68E or Pincher RNAi to selectively and effectively block internalization of endogenous surface Trk. The formation of clathrin-independent Trk macroendosomes was not aberrantly caused by overexpression of Trk and/or Pincher, because a similar overexpression of the EGF receptor in neurons resulted in increased formation of EGF receptor-labeled clathrincoated pits and vesicles, as well as the usual variety of early and late endosomal structures (Valdez, Akmentin, and Halegoua, unpublished observations). However, depending on the expression levels of both Trk and Pincher, the complex ruffles and macroendosomes would be expected to normally vary in both size and membrane complexity. Although dynamin is also required for Trk endo- cytosis, it participates more generally in vesicle formation underlying a variety of trafficking and signaling processes (McNiven et al., 2000). Defining the interplay between Pincher and dynamin and the identity of Pincher partners involved in the macroendocytic process will provide additional insights into this unique mode of endocytosis.

The intermediates in the Trk endocytic pathway identified by ultrastructural analysis suggested an atypical pathway for Trk endosomal processing. In neurons overexpressing Trk and/or Pincher, Trk-containing vesicles and MVBs appeared to be processed directly from the macroendosomes. This process was Pincher mediated, because Pincher overexpression enhanced both the number and the size of macroendosomal intermediates and MVBs containing both Trk and Pincher. Pincher was primarily sorted from MVBs into membrane tubules that recycled to the plasma membrane [as in PC12 cells (Shao et al., 2002)], but some also remained associated with the outer membrane of Trk MVBs. Pincher expression had a pronounced inhibitory effect on lysosomal processing and degradation within Trk endosomes, suggesting that the degree of Pincher association with endosomal structures might govern their half-life and thus the lifetime of endosomal signaling.

Pincher mediates the internalization of Trk along axons and dendrites in a similar manner to the cell body. Trk internalization in all neuronal compartments was blocked by expression of the dominant-negative PincherG68E, indicating that Pinchermediated endocytosis was the primary mode of Trk internalization. In contrast to the cell body, Pincher-mediated Trk endocytosis in axonal and dendritic processes appears to involve incomplete endosomal processing, with little evidence of Pincher recycling, suggesting that Trk endosomal structures are associated with Pincher along its route of retrograde transport. Although the mechanics of Pincher sorting and recycling are not yet known, it seems that in axons and dendrites the factors required for these events are either limiting or blocked. The predominant endosomal structure, macroendosome or multivesicular body, that is retrogradely transported may be determined by the relative amounts of Trk and Pincher. Previous studies have shown the presence, by electron microscopy, of NGF-containing vesicles and MVBs in axons in vivo (Delcroix et al., 2003; Weible and Hendry, 2004). The idea that MVBs participate in retrograde transport of the signaling endosome has also been proposed (Weible and Hendry, 2004), but how these may be integrated into the transport process and whether they are long lived are not known. Our finding that Pincher inhibits lysosomal processing in the cell body suggests that the persistence of Pincher specifically in axonal and dendritic endosomes may likewise prevent degradation of Trk endosomes in the axons and dendrites, thus providing for long-range and long-term retrograde transport and functioning of the signaling endosome.

The activated form of the critical downstream effector, Erk5, which mediates retrograde axonal survival signaling by Trk (Watson et al., 2001), was associated with the Pincherinternalized Trk endosomal structures. This indicates that Erk5 has an affinity for and is activated by signaling complexes associated with Trk endosomes. Indeed, in neurons expressing the dominant-negative mutant PincherG68E, activated Erk5 was strongly associated with plasma membrane complexes containing both PincherG68E and accumulated activated Trk that was not internalized. However, when Trk internalization was blocked by a dominant-negative dynaminK44A mutant, Erk5 was not drawn to the Trk that was restricted to the plasma membrane, suggesting that Pincher specifically nucleates a specialized endosomal-signaling complex that carries the retrograde signal. 
Endosome formation and signaling is mediated specifically through the Trk receptor tyrosine kinase. Pincher mediated the endocytosis of the ligand-receptor complex of an EGF/TrkB chimera that contained activated Trk, indicating that Trk endocytosis does not require ligand binding to the p75 NT receptor. This result is consistent with previous studies showing that EGFR/TrkB chimeras can mediate long-term signaling for neuronal differentiation of PC12 cells (Wang et al., 1996) and that internalization of p75 can follow a route of internalization distinct from TrkA (Bronfman et al., 2003). For both TrkA and TrkB, Pincher mediates the internalization of activated and autophosphorylated receptors, whether or not the activation is caused by NT binding. The independence of NT binding is consistent with previous studies reporting densitydependent Trk activation (Hempstead et al., 1992; Saragovi et al., 1998) and Trk retrograde signaling in the absence of ligand (MacInnis and Campenot, 2002; Heerssen et al., 2004).

Pincher plays a general role in mediating endosomal signaling for the neurotrophins and their Trk receptors in neurons of the CNS and peripheral nervous system. Retrograde axonal signaling via Trk receptors has been best demonstrated to be crucial for survival of peripheral neurons. We show that Pincher-mediated Trk macroendocytosis is responsible for this event. Interestingly, Trk retrograde signaling in hippocampal dendrites has been linked to long-term potentiation (LTP) (Patterson et al., 2001); the finding that Pinchermediated Trk endocytosis occurs in hippocampal dendrites suggests that LTP may involve retrograde signaling mechanisms similar to those in axons. Throughout the nervous system, families of growth factor/cytokine receptors are recruited for long-term and retrograde signaling. It will be of interest to determine whether Pinchermediated macroendocytosis is a more universal mechanism for mediating this class of signaling events.

\section{References}

Beattie EC, Zhou J, Grimes ML, Bunnett NW, Howe CL, Mobley WC (1996) A signaling endosome hypothesis to explain NGF actions: potential implications for neurodegeneration. Cold Spring Harb Symp Quant Biol 61:389-406.

Bilderback TR, Gazula VR, Lisanti MP, Dobrowsky RT (1999) Caveolin interacts with Trk A and p75(NTR) and regulates neurotrophin signaling pathways. J Biol Chem 274:257-263.

Bronfman FC, Tcherpakov M, Jovin TM, Fainzilber M (2003) Ligandinduced internalization of the p75 neurotrophin receptor: a slow route to the signaling endosome. J Neurosci 23:3209-3220.

Campenot RB (1982) Development of sympathetic neurons in compartmentalized cultures. II. Local control of neurite survival by nerve growth factor. Dev Biol 93:13-21.

Campenot RB, MacInnis BL (2004) Retrograde transport of neurotrophins: fact and function. J Neurobiol 58:217-229.

Craig AM, Banker G (1994) Neuronal polarity. Annu Rev Neurosci 17:267-310

Delcroix JD, Valletta JS, Wu C, Hunt SJ, Kowal AS, Mobley WC (2003) NGF signaling in sensory neurons: evidence that early endosomes carry NGF retrograde signals. Neuron 39:69-84.

Ehlers MD, Kaplan DR, Price DL, Koliatsos VE (1995) NGF-stimulated retrograde transport of trkA in the mammalian nervous system. J Cell Biol 130:149-156

Fryer RH, Kaplan DR, Feinstein SC, Radeke MJ, Grayson DR, Kromer LF (1996) Developmental and mature expression of full-length and truncated TrkB receptors in the rat forebrain. J Comp Neurol 374:21-40.

Geetha T, Wooten MW (2003) Association of the atypical protein kinase C-interacting protein p62/ZIP with nerve growth factor receptor TrkA regulates receptor trafficking and Erk5 signaling. J Biol Chem 278:4730-4739.

Ginty DD, Segal RA (2002) Retrograde neurotrophin signaling: Trk-ing along the axon. Curr Opin Neurobiol 12:268-274.

Greene LA, Tischler AS (1976) Establishment of a noradrenergic clonal line of rat adrenal pheochromocytoma cells which respond to nerve growth factor. Proc Natl Acad Sci USA 73:2424-2428.
Guilherme A, Soriano NA, Bose S, Holik J, Bose A, Pomerleau DP, Furcinitti P, Leszyk J, Corvera S, Czech MP (2004) EHD2 and the novel EH domain binding protein EHBP1 couple endocytosis to the actin cytoskeleton. J Biol Chem 279:10593-10605.

Halegoua S, Armstrong RC, Kremer NE (1991) Dissecting the mode of action of a neuronal growth factor. Curr Top Microbiol Immunol 165:119-170.

Heerssen HM, Pazyra MF, Segal RA (2004) Dynein motors transport activated Trks to promote survival of target-dependent neurons. Nat Neurosci 7:596-604.

Hempstead BL, Rabin SJ, Kaplan L, Reid S, Parada LF, Kaplan DR (1992) Overexpression of the trk tyrosine kinase rapidly accelerates nerve growth factor-induced differentiation. Neuron 9:883-896.

Hendry IA, Stockel K, Thoenen H, Iversen LL (1974) The retrograde axonal transport of nerve growth factor. Brain Res 68:103-121.

Howe CL, Mobley WC (2004) Signaling endosome hypothesis: a cellular mechanism for long distance communication. J Neurobiol 58:207-216.

Howe CL, Valletta JS, Rusnak AS, Mobley WC (2001) NGF signaling from clathrin-coated vesicles: evidence that signaling endosomes serve as a platform for the Ras-MAPK pathway. Neuron 32:801-814.

Huang CS, Zhou J, Feng AK, Lynch CC, Klumperman J, DeArmond SJ, Mobley WC (1999) Nerve growth factor signaling in caveolae-like domains at the plasma membrane. J Biol Chem 274:36707-36714.

Jullien J, Guili V, Derrington EA, Darlix JL, Reichardt LF, Rudkin BB (2003) Trafficking of TrkA-green fluorescent protein chimerae during nerve growth factor-induced differentiation. J Biol Chem 278:8706-8716.

Kuruvilla R, Zweifel LS, Glebova NO, Lonze BE, Valdez G, Ye H, Ginty DD (2004) A neurotrophin signaling cascade coordinates sympathetic neuron development through differential control of TrkA trafficking and retrograde signaling. Cell 118:243-255.

Lein PJ, Beck HN, Chandrasekaran V, Gallagher PJ, Chen HL, Lin Y, Guo X, Kaplan PL, Tiedge H, Higgins D (2002) Glia induce dendritic growth in cultured sympathetic neurons by modulating the balance between bone morphogenetic proteins (BMPs) and BMP antagonists. J Neurosci 22:10377-10387.

Levi-Montalcini R (1987) The nerve growth factor 35 years later. Science 237:1154-1162.

Lewin GR, Barde YA (1996) Physiology of the neurotrophins. Annu Rev Neurosci 19:289-317.

MacInnis BL, Campenot RB (2002) Retrograde support of neuronal survival without retrograde transport of nerve growth factor. Science 295:1536-1539.

Maher MP, Pine J, Wright J, Tai YC (1999) The neurochip: a new multielectrode device for stimulating and recording from cultured neurons. J Neurosci Methods 87:45-56.

Mains RE, Patterson PH (1973) Primary cultures of dissociated sympathetic neurons. I. Establishment of long-term growth in culture and studies of differentiated properties. J Cell Biol 59:329-345.

Manders E, Verbeek F, Aten J (1993) Measurement of colocalization of objects in dual-color confocal images. J Microsc 169:375-382.

Matsuoka Y, Li X, Bennett V (1998) Adducin is an in vivo substrate for protein kinase C: phosphorylation in the MARCKS-related domain inhibits activity in promoting spectrin-actin complexes and occurs in many cells, including dendritic spines of neurons. J Cell Biol 142:485-497.

McNiven MA, Cao H, Pitts KR, Yoon Y (2000) The dynamin family of mechanoenzymes: pinching in new places. Trends Biochem Sci 25:115-120.

Mintz L, Galperin E, Pasmanik-Chor M, Tulzinsky S, Bromberg Y, Kozak CA, Joyner A, Fein A, Horowitz M (1999) EHD1-an EH-domain-containing protein with a specific expression pattern. Genomics 59:66-76.

Patterson SL, Pittenger C, Morozov A, Martin KC, Scanlin H, Drake C, Kandel ER (2001) Some forms of cAMP-mediated long-lasting potentiation are associated with release of $\mathrm{BDNF}$ and nuclear translocation of phospho-MAP kinase. Neuron 32:123-140.

Riccio A, Pierchala BA, Ciarallo CL, Ginty DD (1997) An NGF-TrkAmediated retrograde signal to transcription factor CREB in sympathetic neurons. Science 277:1097-1100.

Saragovi HU, Zheng W, Maliartchouk S, DiGugliemo GM, Mawal YR, Kamen A, Woo SB, Cuello AC, Debeir T, Neet KE (1998) A TrkA-selective, fast internalizing nerve growth factor-antibody complex induces trophic but not neuritogenic signals. J Biol Chem 273:34933-34940.

Sato Y, Takahashi M, Shibukawa Y, Jain SK, Hamaoka R, Miyagawa J, Yagi- 
numa Y, Honke K, Ishikawa M, Taniguchi N (2001) Overexpression of $\mathrm{N}$-acetylglucosaminyltransferase III enhances the epidermal growth factor-induced phosphorylation of ERK in HeLaS3 cells by up-regulation of the internalization rate of the receptors. J Biol Chem 276:11956-11962.

Segal RA (2003) Selectivity in neurotrophin signaling: theme and variations. Annu Rev Neurosci 26:299-330.

Shao Y, Akmentin W, Toledo-Aral JJ, Rosenbaum J, Valdez G, Cabot JB, Hilbush BS, Halegoua S (2002) Pincher, a pinocytic chaperone for nerve growth factor/TrkA signaling endosomes. J Cell Biol 157:679-691.

Tsui-Pierchala BA, Ginty DD (1999) Characterization of an NGF-P-TrkA retrograde-signaling complex and age-dependent regulation of TrkA phosphorylation in sympathetic neurons. J Neurosci 19:8207-8218.

Vaillant AR, Mazzoni I, Tudan C, Boudreau M, Kaplan DR, Miller FD (1999) Depolarization and neurotrophins converge on the phosphatidylinositol 3-kinase-Akt pathway to synergistically regulate neuronal survival. J Cell Biol 146:955-966.

Wang JK, Xu H, Li HC, Goldfarb M (1996) Broadly expressed SNT-like proteins link FGF receptor stimulation to activators of Ras. Oncogene 13:721-729.
Watson FL, Heerssen HM, Moheban DB, Lin MZ, Sauvageot CM, Bhattacharyya A, Pomeroy SL, Segal RA (1999) Rapid nuclear responses to target-derived neurotrophins require retrograde transport of ligandreceptor complex. J Neurosci 19:7889-7900.

Watson FL, Heerssen HM, Bhattacharyya A, Klesse L, Lin MZ, Segal RA (2001) Neurotrophins use the Erk5 pathway to mediate a retrograde survival response. Nat Neurosci 4:981-988.

Weible II MW, Hendry IA (2004) What is the importance of multivesicular bodies in retrograde axonal transport in vivo? J Neurobiol 58:230-243.

Yano H, Lee FS, Kong H, Chuang J, Arevalo J, Perez P, Sung C, Chao MV (2001) Association of Trk neurotrophin receptors with components of the cytoplasmic dynein motor. J Neurosci 21:RC125(1-7).

Ye H, Kuruvilla R, Zweifel LS, Ginty DD (2003) Evidence in support of signaling endosome-based retrograde survival of sympathetic neurons. Neuron 39:57-68.

Zhang Y, Moheban DB, Conway BR, Bhattacharyya A, Segal RA (2000) Cell surface Trk receptors mediate NGF-induced survival while internalized receptors regulate NGF-induced differentiation. J Neurosci 20:5671-5678. 